\title{
RNAi-mediated downregulation of asparaginase-like protein 1 inhibits growth and promotes apoptosis of human cervical cancer line SiHa
}

\author{
XIAO-FENG LV ${ }^{1 *}$, HAN-QING HONG ${ }^{1 *}$, LING LIU $^{1 *}$, SHI-HONG CUI $^{1 *}$, \\ CHEN-CHEN REN $^{1}$, HONG-YU LI ${ }^{1}$, XIAO-AN ZHANG ${ }^{2}$, LIN-DONG ZHANG ${ }^{1}$, \\ TIAN-XIANG WEI $^{1}$, JIN-JIN LIU ${ }^{1}$, WEN-YING XING ${ }^{1}$, HAN FU $^{1}$ and SHU-JUN YAN ${ }^{1}$
}

Departments of ${ }^{1}$ Obstetrics and Gynecology, and ${ }^{2}$ Imaging, The Third Affiliated Hospital of Zhengzhou University, Zhengzhou, Henan 450052, P.R. China

Received December 21, 2017; Accepted May 9, 2018

DOI: $10.3892 / \mathrm{mmr} .2018 .9018$

\begin{abstract}
Asparaginase like 1 (ASRGL1) protein belongs to the $\mathrm{N}$-terminal nucleophile group, cleaving the isoaspartyl-dipeptides and L-asparagine by adding water. It tends to be overexpressed in cancerous tumors including ovarian cancer and breast tumors. The present study assessed the potential ability of ASRGL1 as a molecular target in gene-based cervical cancer treatment. The protein expression level of ASRGL1 was determined in paraffin-embedded tumor specimen by immunohistochemistry. Additionally, in order to assess the activity of ASRGL1 during the process of cervical cancer cell multiplication, ASRGL1-short hairpin (sh) RNA-expressing lentivirus was established, which was used to infect SiHa cells. The Cellomics ArrayScan VT1 Reader identified the influence of downregulation on SiHa caused by RNA interference-intervened ASRGL1. Flow cytometric analysis was also performed to evaluate the influence. The cyclin dependent kinase (CDK2), cyclin A2, B-cell lymphoma 2 (Bcl-2) and Bcl-2-associated X protein (Bax) expression levels were assessed by western blot analysis. ASRGL1 was observed to be overexpressed in cervical cancer tissues when compared with the adjacent normal tissues. The knockdown of ASRGL1 in SiHa by ASRGL1-shRNA lentivirus infection significantly inhibited cell growth and enhanced cellular apoptosis; the cells were also captured during the $\mathrm{S}$ phase. The knockdown of
\end{abstract}

Correspondence to: Dr Shi-Hong Cui, Department of Obstetrics and Gynecology, The Third Affiliated Hospital of Zhengzhou University, 7 Kangfu Front Street, Erqi, Zhengzhou, Henan 450052, P.R. China

E-mail: shihongcui@126.com

*Contributed equally

Key words: asparaginase like 1, proliferation, cervical cancer, apoptosis, RNA interference
ASRGL1 expression led to the increased expression of Bax and decreased expression of Bcl-2, CDK2 and cyclin A2. In conclusion, ASRGL1 was closely associated with growth and apoptosis in cervical cancer. Therefore, ASRGL1 may be a novel, potentially effective anti-cervical cancer therapy.

\section{Introduction}

Cervical cancer is one of the most common destructive tumors of obstetrics and gynecology, severely endangering the health of women; however, an effective method for gene therapy is yet lacking $(1,2)$. Despite that the advanced surgery and chemotherapy can enhance the therapeutic effect, there is still a high death rate owing to the recurrence of the disease in patients as well as drug resistance in chemotherapy $(3,4)$. Vaccines cannot treat or protect all types of cancer patients or human papillomavirus (HPV) infection $(5,6)$. The occurrence of cervical cancer is a complex, multifaceted process; a hazardous HPV infection has been recognized as the crucial factor for cervical cancer (7-9). In China, 262,000 new cervical cancer cases are identified, and $\sim 28,000$ women are deceased each year (10). Therefore, the development of advanced medical therapy against the disease is of vital significance.

Asparaginase like 1 (ASRGL1) also termed as CRASH, is an enzyme that hydrolyzes asparagine or glutamine into aspartic acid and glutamic acid (11); it has been used to treat acute lymphoblastic leukemia (ALL) for decades (12-14). However, the role of ASRGL1 in gynecological tumors has a different perspective. Studies on endometrial cancer found that ASRGL1 destitution is related to aggressive disease and meager survival $(15,16)$. On the contrary, a high level of ASRGL1 was identified in mammary and ovarian cancers $(17,18)$. Furthermore, there is no report about ASRGL1 expression and function in cervical cancer to date.

In this study, a high expression of ASRGL1 is shown to be present in cervical cancer tissue samples. Then, ASRGL1-short hairpin (sh) RNA-expressing lentivirus was adopted to explore the influence of ASRGL1 knockdown on human cervical cancer SiHa cells in vitro. 


\section{Materials and methods}

Tissue samples and Cell lines. 32 cervical cancer tissue specimens and paracancerous tissue specimens were obtained from patients who underwent surgical at the Gynecology and Obstetrics Department of the Third Affiliated Hospital of Zhengzhou University (Zhengzhou, China) from January 2017 to October 2017. All patients were not receiving radiotherapy or chemotherapy before the surgical. All patients involved in the study were informed, in addition to being provided with informed consent documentation, which they subsequently signed. Experiments were approved by the Ethics Committee of clinical trials of the Third Affiliated Hospital of Zhengzhou University. SiHa (cervical squamous cell carcinoma) and HeLa (cervical adenocarcinoma) cell lines were bought from the Shanghai Institute for Biology Sciences of the Chinese Academy of Sciences. The cell lines were cultured in DMEM medium with $10 \%(\mathrm{v} / \mathrm{v})$ prenatal bovine serum, which is not heat-activated (all from Gibco ${ }^{\circledR}$; Thermo Fisher Scientific, Inc., Waltham, MA, USA), $100 \mathrm{mg} / \mathrm{ml}$ streptomycin, and $100 \mathrm{U} / \mathrm{ml}$ penicillin (Sangon Co., Ltd, Shanghai, China) at $37^{\circ} \mathrm{C}$ in a humidified incubator with $5 \% \mathrm{CO}_{2}$.

Immunohistochemistry. Tissues were fixed in formalin and embedded in paraffin wax. The paraffin-embedded samples were cut into 4-mm-thick, then were deparaffinized and rehydrated in xylene and serially diluted alcohol solutions. Slides were heated by microwaving in $0.01 \mathrm{M}$ sodium citrate solution for $15 \mathrm{~min}$ to retrieve antigen. Subsequently, the slides were incubated with ASRGL1 rabbit polyclonal antibody (1:100; Abcam, Cambridge, UK) at $4^{\circ} \mathrm{C}$ overnight. Then, each slice was incubated with second antibody for $30 \mathrm{~min}$. Finally, all slides were stained with diaminobenzidine followed by the hematoxylin was applied to counterstain. As a negative control (NC), the primary antibody was replaced with PBS. All the images were analyzed by conventional optical microscopy.

Reverse transcription-quantitative polymerase chain reaction $(R T-q P C R)$. The cellular RNA from SiHa cells was extracted by TRIzol (Invitrogen, Shanghai, China). Subsequently, $2 \mu \mathrm{g}$ mRNA was reverse transcribed into cDNA. The primers were designed as follows: ASRGL1 forward, 5'-CGAGTTCAACGC AGGTTGTG-3' and reverse, 5'-GGGATTTGCTATACACTG GACTG-3'; GAPDH forward, 5'-TGACTTCAACAGCGA CACCCA-3' and 5'-CACCCTGTTGCTGTAGCCAAA-3'. qPCR was performed using the SYBR-Green kit (Takara Biotechnology Co., Ltd., Dalian, China) and the ABI 7500 Real-time PCR system (Applied Biosystems; Thermo Fisher Scientific, Inc.). Relative expression as determined using the $2^{-\Delta \Delta C q}$ method as described previously (19). The RT-qPCR reaction was as follows: $95^{\circ} \mathrm{C}$ for a period of $15 \mathrm{sec}$, followed by 45 cycles including denaturation at $95^{\circ} \mathrm{C}$ for $5 \mathrm{sec}$, annealing at $45-62^{\circ} \mathrm{C}$ for $30 \mathrm{sec}$. The PCR amplification of GAPDH and $A S R G L 1$ provided an amplicon of 121 and $127 \mathrm{bp}$, respectively.

Recombinant lentiviral vector production and cell infection. GeneChem Co., Ltd. (Shanghai, China) made the blueprint of the mutually complementary DNA sequence (5'-CAGTCCAGT GTATAGCAAA-3') of ASRGL1. The knockdown efficiencies of these oligonucleotides were tested by incorporating into the lentivirus-based psc14173 (GeneChem Co.,Ltd.) via Agel/EcoRI sites. The lentivirus particles functioned as described previously (20). With respect to the lentivirus infection, SiHa cells were seeded in 6-well plates. Then, ASRGL1-shRNA-lentivirus or NC lentivirus was added according to the multiplicity of infection (MOI). The cells were examined using fluorescence microscope (Olympus, Tokyo, Japan) after three days.

Western blot analysis. After several washes with cold phosphate-buffered saline (PBS), the cells were solubilized in precooled $2 \mathrm{X}$ lysis buffer (100 mM Tris, $\mathrm{pH} 6.8,10 \%$ glycerol, $4 \%$ SDS, $2 \% 2$-ME, $10 \mathrm{mM}$ EDTA) for $30 \mathrm{~min}$ on ice. Then, the supernatants were collected after the lysates were centrifuged at $14,000 \times \mathrm{g}, 4^{\circ} \mathrm{C}$ for $10 \mathrm{~min}$. An equivalent amount of protein is separated by $12 \%$ SDS-PAGE and transferred on PVDF membrane (Millipore, Bedford, MA). Then, the membrane was blocked in 5\% fat-free milk, in TBST buffer, followed by probing with the anti-ASRGL1 (1:1,000), Bcl-2-associated $\mathrm{X}$ protein (anti-Bax; 1:1,000), anti-B-cell lymphoma 2 (Bcl-2; 1:1,000), anti-cyclin dependent kinase (CDK2; 1:1,000), anti-cyclin A2 (1:1,000; all Abcam) antibodies at $4^{\circ} \mathrm{C}$ overnight. GAPDH (1:2,000; Santa Cruz Biotechnology, Inc., Dallas, TX, USA) is an endogenous control. After 3 washes in TBST, the membrane was incubated with the HRP-conjugated goat anti-mouse and goat anti-rabbit secondary antibody (1:5,000; Santa Cruz Biotechnology, Inc.) for $2 \mathrm{~h}$ at room temperature. Finally, it was detected using ECL reagent (ECL-Plus kit; Amersham, Piscataway, NJ, USA).

Cell proliferation experiment. SiHa cells in the logarithmic stage were digested and resuspended; 2,000 cells/well were seeded into 96-well plates. Each experiment was performed three times independently. Since day 2, Cellomics ArrayScan VT1 Readers (Cellomics, Inc., Pittsburgh, PA, USA) calculated the cell number once a day at an interval of five days. By adjusting the analysis settings of input parameters, the number of cells with green fluorescence in each scan orifice were calculated accurately. Finally, the cell proliferation curve was plotted.

Analysis of cell cycle. Cells were infected with ASRGL1 shRNA lentivirus or control and were cultured to $80 \%$ confluency. Subsequently, the cells were digested, resuspended, and centrifuged at 1,300 rpm for $5 \mathrm{~min}$, washed in chilled PBS, and fixed in $75 \%$ alcohol for $1 \mathrm{~h}$, followed by staining with propidium iodide (PI; $50 \mu \mathrm{g} / \mathrm{ml}$, Sigma-Aldrich ${ }^{\circledR}$, St. Louis, MO, USA) in the presence of RNase A (100 $\mu \mathrm{g} / \mathrm{ml}$; Fermentas ${ }^{\circledR}$, Shanghai, China). The cell cycle was analyzed using BD FACSCalibur flow cytometer (FCM; BD Biosciences, San Diego, CA, USA).

Apoptotic assay. Cells were seeded into 6-well plates and transfected with ASRGL1-shRNA or NC lentivirus for $72 \mathrm{~h}$. Then, the cells were digested, resuspended, centrifuged at $1,300 \mathrm{rpm}$ for $5 \mathrm{~min}$, washed in cold PBS and $1 \mathrm{X}$ binding buffer, followed by resuspension in $1 \mathrm{ml} 1 \mathrm{X}$ staining buffer, and $5 \mathrm{ml}$ Annexin V-APC (eBioscience, San Diego, CA, USA) into $100 \mathrm{ml}$ cell suspension. The reaction was incubated in the dark for $15 \mathrm{~min}$. The cells were analyzed by FCM.

Data analysis. The cell cultures were analyzed in triplicate using the SPSS version 21.0 software (IBM SPSS, Corp., 


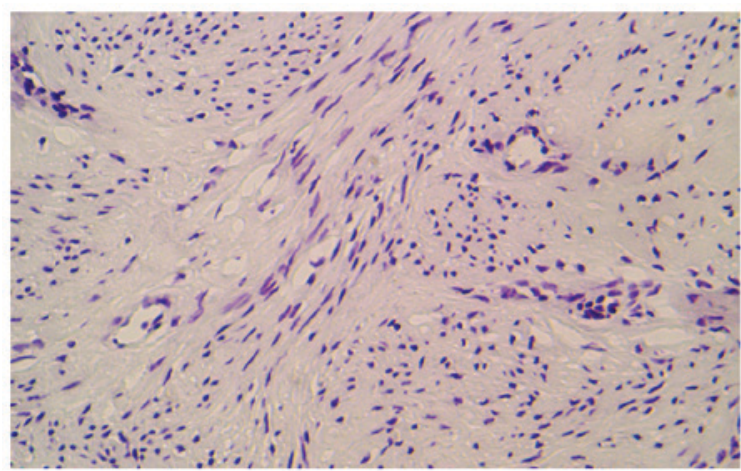

Control

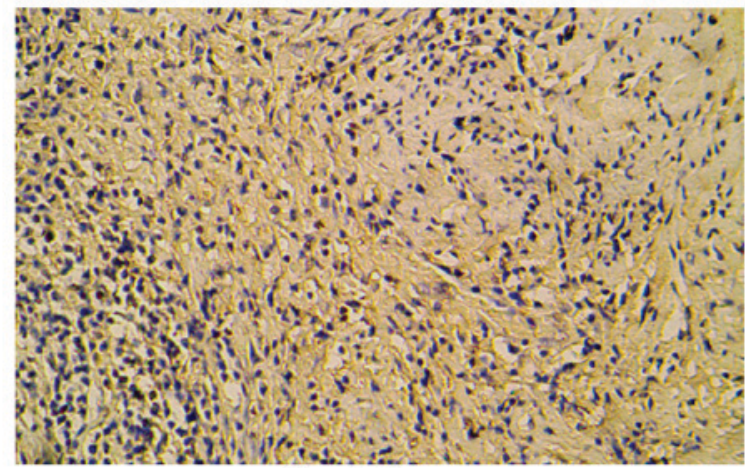

Cervical cancer

Figure 1. Asparaginase like 1 expression level in cervical cancer tissues was measured by immunohistochemistry (magnification, x200).

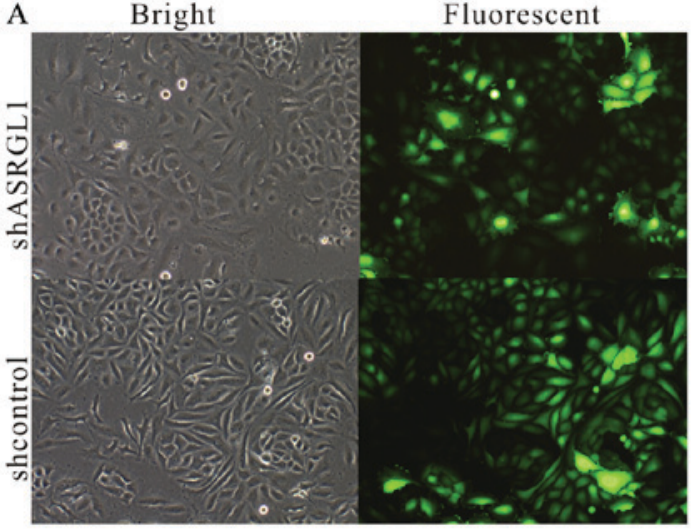

C

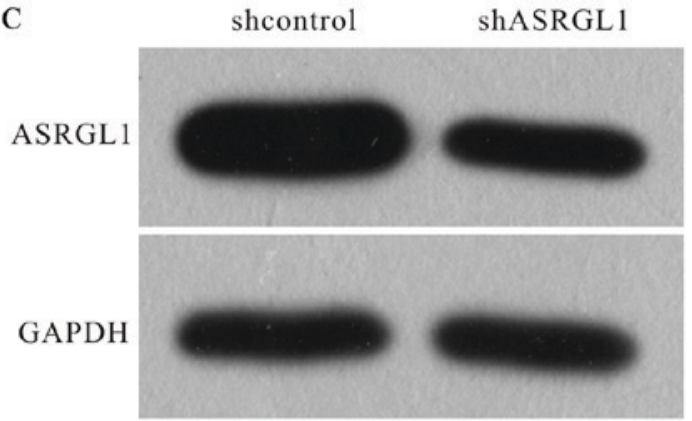

B

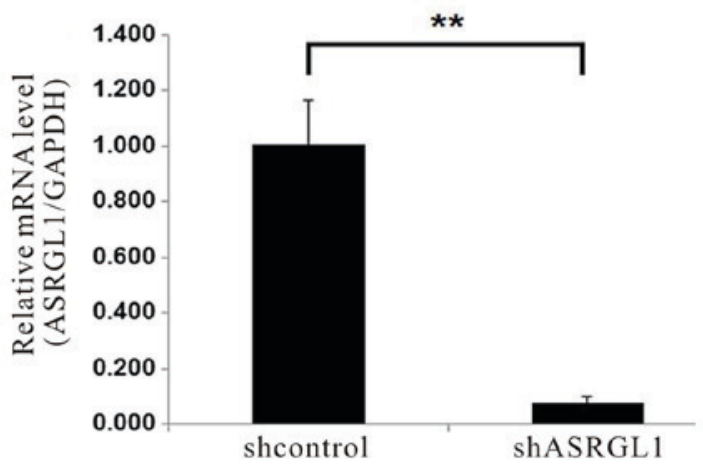

D

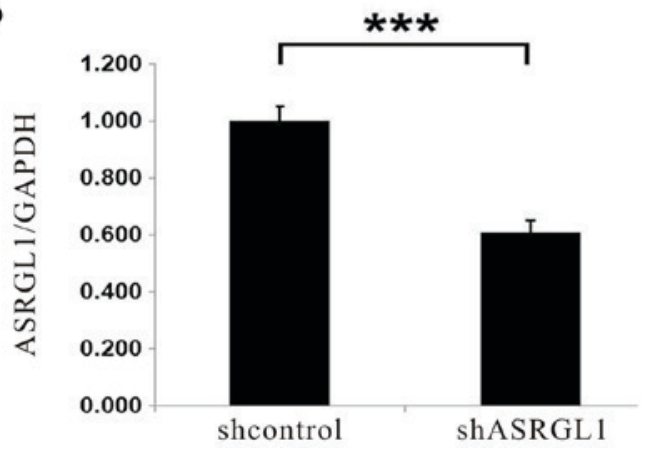

Figure 2. Knockdown efficiency of ASRGL1. (A) Following the infection of SiHa cells with ASRGL1 shRNA lentivirus and NC shRNA lentivirus for 3 days, the cells were observed by fluorescence microscope at magnification, x100. (B) The ASRGL1 mRNA level was measured by reverse transcription-quantitative polymerase chain reaction and was revealed to be significantly decreased in cell lines infected with ASRGL1 shRNA lentivirus. (C) Western blot analysis of the ASRGL1 protein expression level in SiHa cells infected with NC shRNA lentivirus and ASRGL1 shRNA lentivirus, respectively. (D) Quantitative analysis of western blotting bands. Each bar represents the mean \pm standard error mean from three independent experiments. ${ }^{* *} \mathrm{P}<0.01$ and ${ }^{* * * *} \mathrm{P}<0.001$, as indicated. ASRGL1, asparaginase like 1; sh, short hairpin; NC, negative control.

Armonk, NY, USA). The original data were presented as mean \pm standard deviation (SD). The discrepancies in ASRGL1 knockdown and control cells were comparison using Student's t-test. $\mathrm{P}<0.05$ was considered to indicate a statistically significant difference.

\section{Results}

Expression of ASRGL1 in clinical cervical carcinoma tissues. The ASRGL1 proteins were mainly located in the cytoplasm and was found to be overexpressed in cervical tissues from patients with cervical cancer when compared with the paracancerous tissue specimens, as analyzed by immunohistochemistry (Fig. 1) $(\mathrm{P}<0.05)$.

Knockdown efficiency of ASRGL1. The efficiency of ASRGL1 in SiHa cervical cancer cells was examined by infecting the cells with ASRGL1 shRNA lentivirus and NC shRNA lentivirus-expressing GFP, respectively. Then, we examined the fluorescence level of GFP protein to determine the infection efficiency. As seen in Fig. 2A, $72 \mathrm{~h}$ after infection, $>80 \%$ cells were expressing GFP as assessed by fluorescence microscopy. The mRNA and protein expression level of ASRGL1 after shRNA infection was 

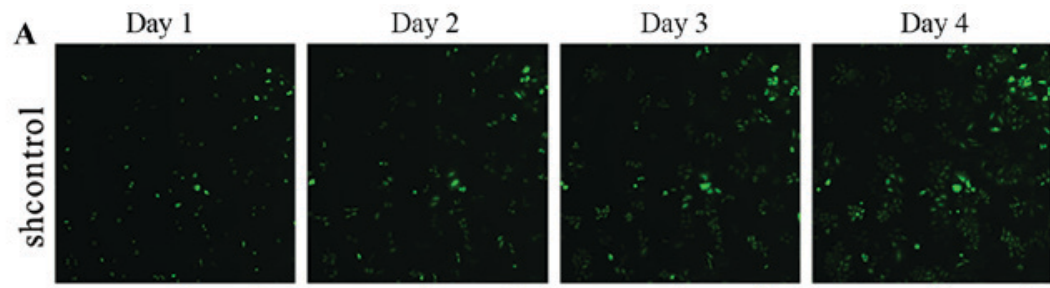

Day 5
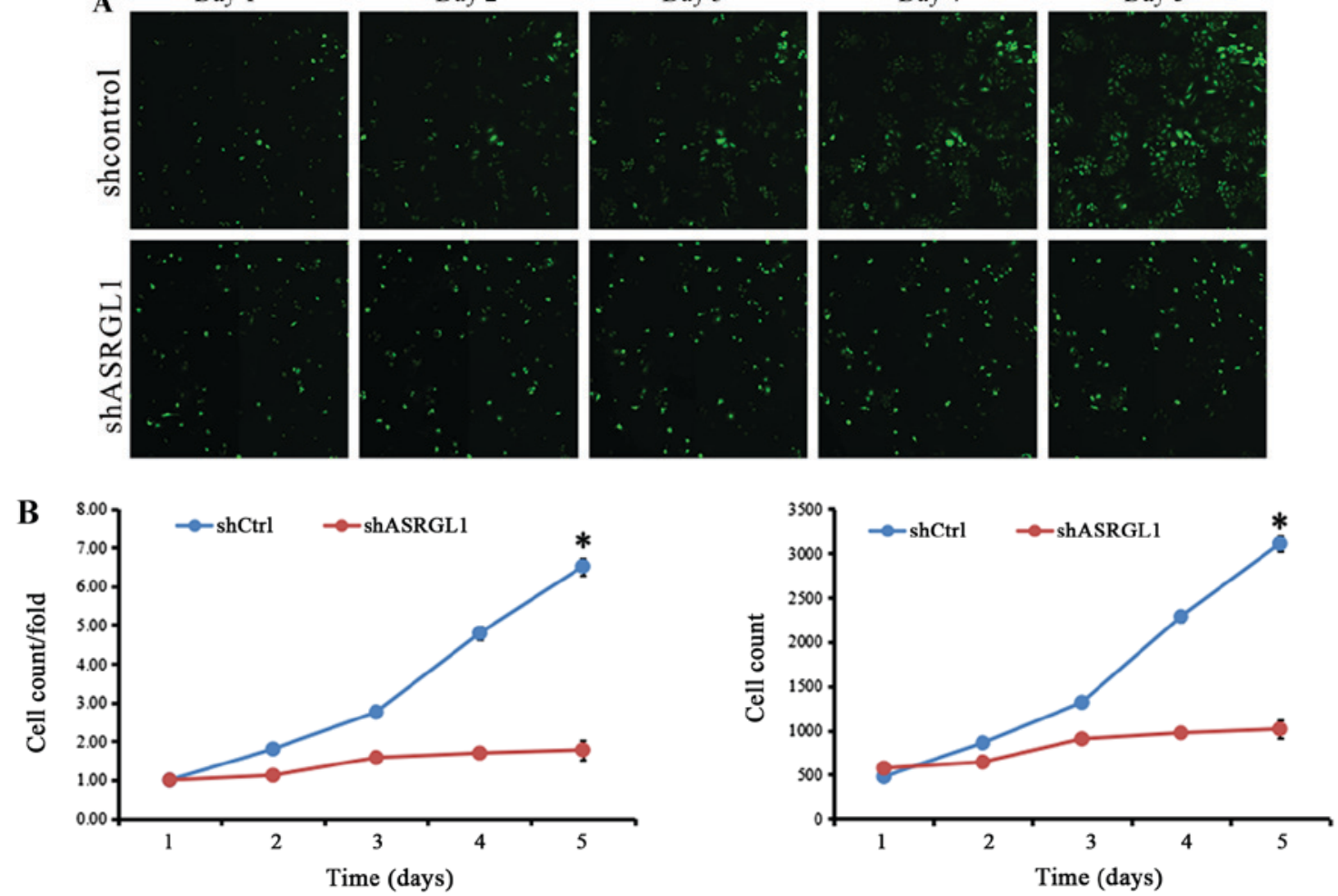

Figure 3. Impact caused by ASRGL1 knockdown on SiHa cells development. (A) The cells were infected with the NC shRNA or ASRGL1-shRNA lentivirus to assess the advanced cell growth (magnification, x100). (B) The cells infected with ASRGL1 shRNA lentivirus and NC shRNA lentivirus were evaluated by Cellomics ArrayScan VT1 Readers steadily for a period of 5 days. "P<0.05 vs. shASRGL1. ASRGL1, asparaginase like 1; sh, short hairpin; NC, negative control.
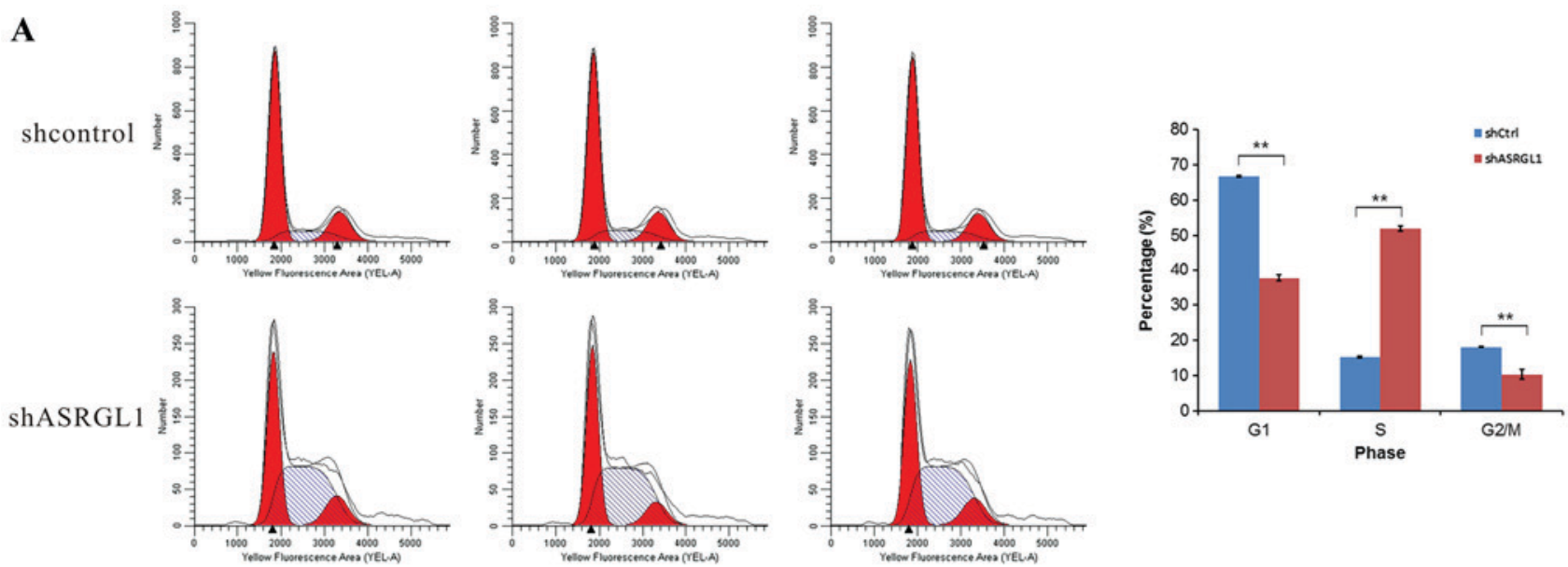

B

CDK2

Cyclin A2
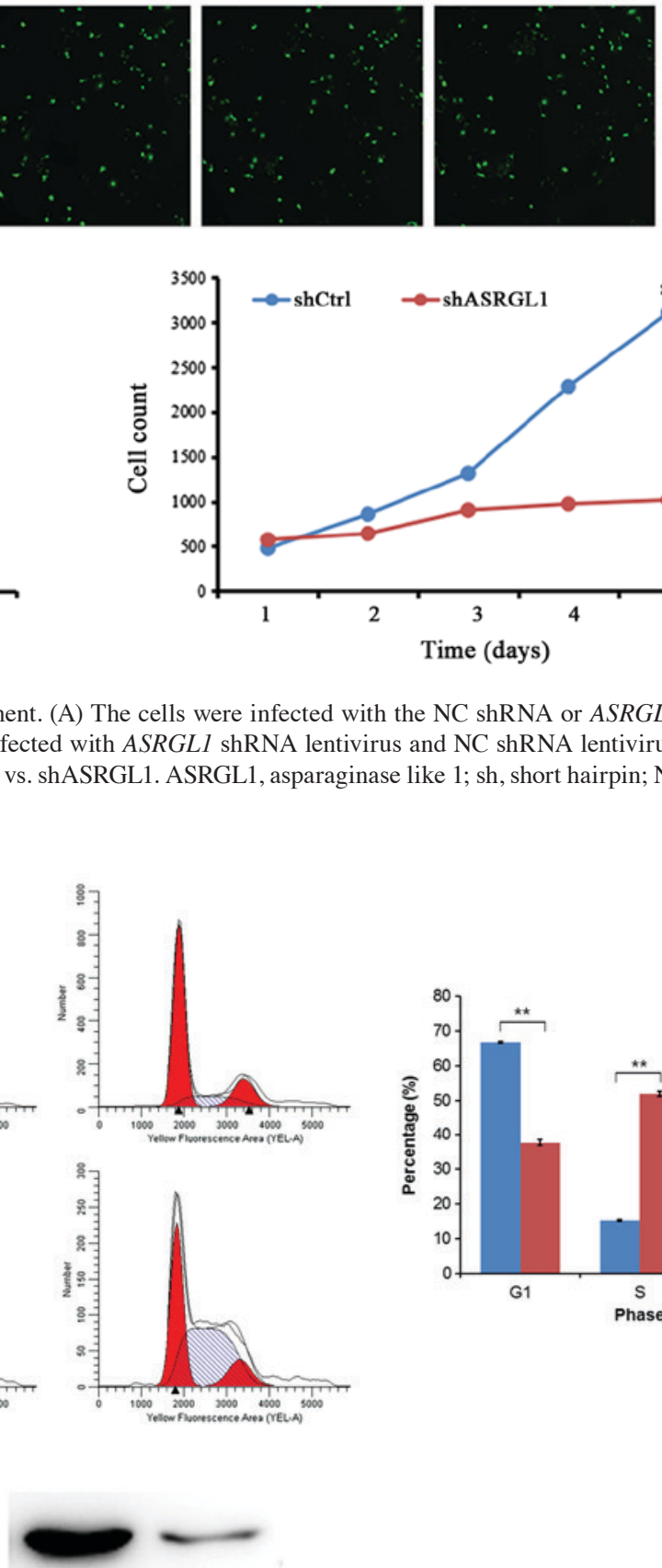

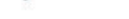

GAPDH

shcontrol shASRGL1

Figure 4. Influence of downregulated ASRGL1 on cell cycle. (A) SiHa cells were infected with ASRGL1 shRNA lentivirus or control, and cultured to $80 \%$ confluency, as detected by flow cytometry. ${ }^{* *} \mathrm{P}<0.01$, as indicated. (B) The expression levels of cyclin A2 and CDK2 in the experimental and control groups were detected by western blotting. ASRGL1, asparaginase like 1; sh, short hairpin; CDK2, cyclin dependent kinase 2. 
A

shcontrol

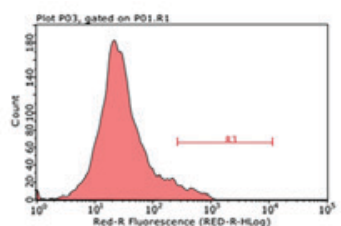

Annexin $\mathrm{V}$

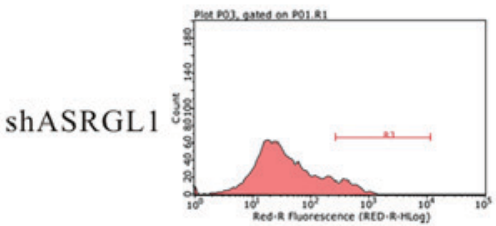

Annexin V

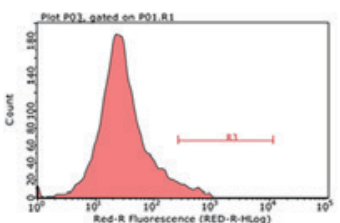

Annexin V

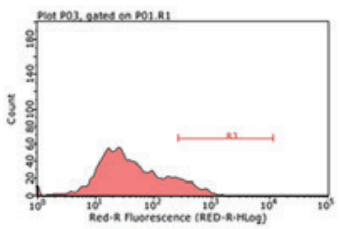

Annexin V

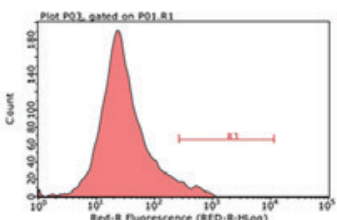

Annexin V

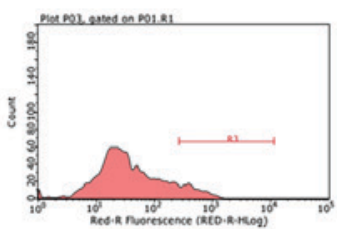

Annexin V

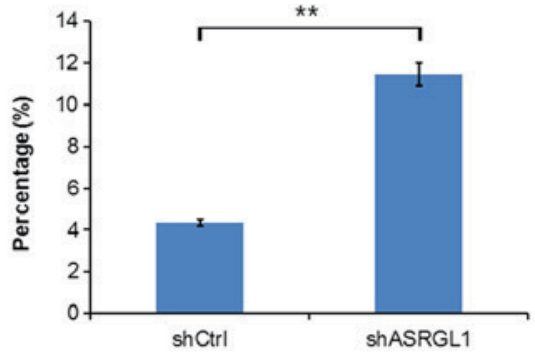

B

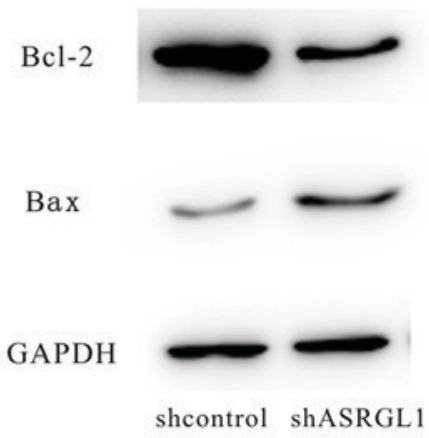

Figure 5. Silencing ASRGL1 in SiHa cells leads to cell apoptosis. (A) Following 3 days of infection, the SiHa cells were stained using Annexin V-APC and analyzed by flow cytometry. ${ }^{* *} \mathrm{P}<0.01$, as indicated. (B) The expression levels of Bax and Bcl-2 in cells transfected with shASRGL1 lentivirus or the control. ASRGL1, asparaginase like 1; sh, short hairpin; Bcl-2, B-cell lymphoma 2; Bax, Bcl-2-associated X protein; APC, allophycocyanin; Ctrl, control.

evaluated by quantitative PCR and western blot analysis, respectively. As observed in Fig. 2B, the ASRGL1 mRNA level was decreased by almost $90 \%$ in cell lines infected with ASRGL1 shRNA lentivirus as compared to the NC group. Furthermore, Fig. 2C showed the downregulation of ASRGL1 protein expression in $\mathrm{SiHa}$ cells infected with ASRGL1 shRNA lentivirus. Fig. 2D, the quantitative analysis of western blotting brands.

Knockdown of ASRGL1 in SiHa cells inhibits cell multiplication. In order to evaluate the function of ASRGL1 in the proliferation of cervical cancer cells, GFP-expressing cells were infected with ASRGLl shRNA lentivirus and NC shRNA lentivirus, respectively using Cellomics ArrayScan VT1 Readers continuously for 5 days. As shown in Fig. 3A, the cells transfected with NC shRNA lentivirus were significantly more as compared to the ASRGL1-shRNA-transfected cells on day $5(\mathrm{P}<0.05)$. Fig. 3B further confirmed that knockdown of ASRGL1 had a dramatic impact on curbing the SiHa cells' number.

Effect of ASRGL1 shRNA on cell cycle. FCM was used to analyze whether the knockdown of ASRGL1 will affect the cell cycle progression in SiHa cells. As illustrated in Fig. 4A, the ASRGL1-shRNA-transfected cells were distributed in G1 phase $(37.71 \pm 0.86 \%, \mathrm{P}<0.01)$; $\mathrm{S}$ phase $(51.95 \pm 0.68 \%$, $\mathrm{P}<0.01)$, and $\mathrm{G} 2 / \mathrm{M}(10.34 \pm 1.31 \%, \mathrm{P}<0.01)$. However, the
NC-shRNA-transfected cells were distributed in G1 phase $(66.62 \pm 0.27 \%, \mathrm{P}<0.01)$; $\mathrm{S}$ phase $(15.30 \pm 0.26 \%, \mathrm{P}<0.01)$, and $\mathrm{G} 2 / \mathrm{M}(18.08 \pm 0.19 \%, \mathrm{P}<0.01)$. Furthermore, the ratios of $\mathrm{S}$ stage cells in ASRGL1-shRNA transfected group were significantly larger than those in the negative shRNA control group $(\mathrm{P}<0.01)$. Additionally, the levels of CDK2 and cyclin A2 were significantly reduced in the ASRGL1 siRNA-transfected cells (Fig. 4B). Cyclin A2 appeared in the late Go, can combine with CDK2 and promote the synthesis of DNA in S phase. Consequently, the knockdown of ASRGL1 might capture the cell cycle during the S stage in $\mathrm{SiHa}$ cells.

Knockdown of ASRGL1 in SiHa cells increases cellular apoptosis. FCM was employed to analyze whether the knockdown of ASRGL1 affected the cell apoptosis in $\mathrm{SiHa}$ cells (Fig. 5A). The rate of apoptosis in the ASRGL1-shRNA exhibited a dramatic increase as compared to the negative shRNA control group (ASRGL1-shRNA $11.483 \pm 0.55 \%$ vs. NC-shRNA $4.36 \pm 0.15 \%, \mathrm{P}<0.05)$. Hence, silencing the expression of ASRGL1 in SiHa cells induces apoptosis. Subsequently, we measured the expression level of cell apoptosis-associated proteins Bax and Bcl-2 after the knockdown of ASRGL1 (Fig. 5B). The proapoptotic protein, Bax, was significantly enhanced, whereas the expression of anti-apoptosis Bcl-2 protein was reduced compared with the control. 


\section{Discussion}

During the present study, the ASRGL1 expression was significantly upregulated in cervical cancer tissue compared with the paracancerous tissue. To explore the function of ASRGL1 in SiHa cells, we used ASRGL1 shRNA lentivirus to inhibit the expression of ASRGL1, which indicated that the loss of ASRGL1 could significantly suppress the proliferation and promote apoptosis in SiHa cells. However, converse results were observed in endometrial carcinoma (16), but similar in mammary and ovarian cancers $(17,18)$. This phenomenon suggested that ASRGL1 was closely associated with the tumor growth and can function as the potential target of cervical cancer gene therapy. There is a striking discrepancy between the expression of ASGRL1 on mRNA and on protein level after lentivirus. This is because the main role of shRNA is in RNA level, and there is also a process of RNA transcription before protein transcription, so the RNA level effect is more obvious. The expression level of cell proapoptotic proteins Bax exhibited a dramatic increase as compared to the negative shRNA control group, indicate that the ASRGL1 may acts as an anti-apoptotic factor in the cell apoptotic process. Moreover, after infection with ASRGL1 shRNA lentivirus, the ratio of cells in $\mathrm{G} 1$ and G2/M stages were declined significantly; however, that in the $\mathrm{S}$ stage was elevated significantly. The cell cycle related proteins Cyclin A2 and CDK2 are the important proteins that promote cells to transform from $S$ phase to $G 2$ phase and contribute the synthesis of DNA $(21,22)$. In this study, the results of western blot analysis show a decline in both CDK2 and Cyclin A2 protein expression compared with the control. This phenomenon indicated that ASRGL1 could inhibit tumor growth by regulating the cell cycle. Thus, the specific molecular mechanism underlying the ASRGL1-regulated cervical cancer cell growth necessitates further investigations in other cervical tumor cell lines.

Owing to the rapid advances in tumor molecular biology and genetic engineering, the genetic treatment is rendered as a cutting-edge therapy mode for tumors (23). RNA interference-based gene therapy can accurately and effectively silence the expression of the target gene. Therefore, identifying the novel biomarker for cervical cancer intervention is essential. The gene encoding ASRGL1, one part of the $\mathrm{N}$-terminal nucleophile (Ntn) hydrolase group (24), occurs in duplicate, and the corresponding transcriptional activation was assessed in endometrial and breast cancers $(16,18)$. As the final step in the degradation of cell surface glycoproteins, ASRGL1 can remove the carbohydrate side chains from asparagine (25), thereby controlling the signaling function from the cell surface, metabolism of tumor cells, and cell growth (11). However, the role $t$ in cervical cancer has not yet been reported. In the current study, the knockdown of ASRGL1 in SiHa cells by ASRGL1-shRNA lentivirus can significantly inhibit cell growth and enhance cellular apoptosis.

In conclusion, ASRGL1 had a close relationship with growth and apoptosis in cervical cancer. The knockdown of ASRGL1 can significantly inhibit the proliferation, promote apoptosis, and arrest the cells in $\mathrm{S}$ phase. Thus, it is a potential method to treat cervical cancer by downregulating ASRGL1 in these overexpressed cells.

\section{Acknowledgements}

Not applicable.

\section{Funding}

The present study was supported by the Science and Technology Department of Henan, China (grant no. 161100311100), National Health and Family Planning Commission of Henan, China (grant no. 201601010) and National Natural Science Foundation of China (grant no. 81702967).

\section{Availability of data and materials}

The datasets used and analyzed during the current study are available from the corresponding author on reasonable request.

\section{Authors' contributions}

$\mathrm{X}-\mathrm{FLV}, \mathrm{H}-\mathrm{QH}$ and $\mathrm{S}-\mathrm{HC}$ conceived and designed the experiments. X-FLV, H-QH, LL, H-YL and C-CR performed the experiments. X-FLV, X-AZ and L-DZ analyzed the data. T-XW, J-JL, W-YX, S-JY and HF contributed reagents, materials and analysis tools. T-XW, J-JL, W-YX, S-JY, HF, $\mathrm{X}-\mathrm{FLV}$ and S-HC wrote the paper, and critically revised the manuscript for important intellectual content. All authors read and approved the final manuscript.

\section{Ethics approval and consent to participate}

All patients involved in the present study provided written informed consent. Experiments were approved by the Ethics Committee of Clinical Trials of The Third Affiliated Hospital of Zhengzhou University.

\section{Consent for publication}

All patients involved in the study provided written informed consent.

\section{Competing interests}

The authors declare that they have no competing interests.

\section{References}

1. Liu W, Gao Q, Chen K, Xue X, Li M, Chen Q, Zhu G and Gao Y: Hiwi facilitates chemoresistance as a cancer stem cell marker in cervical cancer. Oncol Rep 32: 1853-1860, 2014.

2. Torre LA, Bray F, Siegel RL, Ferlay J, Lortet-Tieulent J and Jemal A: Global cancer statistics, 2012. CA Cancer J Clin 65: 87-108, 2015.

3. Yee GP, de Souza P and Khachigian LM: Current and potential treatments for cervical cancer. Curr Cancer Drug Targets 13: 205-220, 2013.

4. Scatchard K, Forrest JL, Flubacher M, Cornes P and Williams C: Chemotherapy for metastatic and recurrent cervical cancer. Cochrane Database Syst Rev 10: CD006469, 2012.

5. Gabrielli B, Bokhari F, Ranall MV, Oo ZY, Stevenson AJ, Wang W, Murrell M, Shaikh M, Fallaha S, Clarke D, et al: Aurora A is critical for survival in HPV-transformed cervical cancer. Mol Cancer Ther 14: 2753-2761, 2015. 
6. Tabrizi SN, Brotherton JM, Kaldor JM, Skinner SR, Liu B, Bateson D, McNamee K, Garefalakis M, Phillips S, Cummins E, et al: Assessment of herd immunity and cross-protection after a human papillomavirus vaccination programme in Australia: A repeat cross-sectional study. Lancet Infect Dis 14: 958-966, 2014

7. Bosch FX, Burchell AN, Schiffman M, Giuliano AR, de Sanjose S, Bruni L, Tortolero-Luna G, Kjaer SK and Muñoz N: Epidemiology and natural history of human papillomavirus infections and type-specific implications in cervical neoplasia. Vaccine 26 (Suppl 10): K1-K16, 2008.

8. Ndiaye C, Mena M, Alemany L, Arbyn M, Castellsagué X, Laporte L, Bosch FX, de Sanjosé S and Trottier H: HPV DNA, E6/E7 mRNA, and p16INK4a detection in head and neck cancers: A systematic review and meta-analysis. Lancet Oncol 15: 1319-1331, 2014.

9. Doorbar J, Egawa N, Griffin H, Kranjec C and Murakami I: Human papillomavirus molecular biology and disease association. Rev Med Virol 25 (Suppl 1): S2-S23, 2015.

10. Zhou M, Wang H, Zhu J, Chen W, Wang L, Liu S, Li Y, Wang L, Liu Y, Yin P, et al: Cause-specific mortality for 240 causes in China during 1990-2013: A systematic subnational analysis for the Global Burden of Disease Study 2013. Lancet 387: 251-272, 2016.

11. Becker FF and Broome JD: L-asparaginase: Inhibition of early mitosis in regenerating rat liver. Science 156: 1602-1603, 1967.

12. Rigouin C, Nguyen HA, Schalk AM and Lavie A: Discovery of human-like L-asparaginases with potential clinical use by directed evolution. Sci Rep 7: 10224, 2017.

13. Shrivastava A, Khan AA, Khurshid M, Kalam MA, Jain SK and Singhal PK: Recent developments in L-asparaginase discovery and its potential as anticancer agent. Crit Rev Oncol Hematol 100: $1-10,2016$

14. Den Boer ML, van Slegtenhorst M, De Menezes RX, Cheok MH, Buijs-Gladdines JG, Peters ST, Van Zutven LJ, Beverloo HB, Van der Spek PJ, Escherich G, et al: A subtype of childhood acute lymphoblastic leukaemia with poor treatment outcome: A genome-wide classification study. Lancet Oncol 10: 125-134, 2009.

15. Edqvist PH, Huvila J, Forsström B, Talve L, Carpén O, Salvesen HB, Krakstad C, Grénman S, Johannesson H, Ljungqvist $\mathrm{O}$, et al: Loss of ASRGL1 expression is an independent biomarker for disease-specific survival in endometrioid endometrial carcinoma. Gynecol Oncol 137: 529-537, 2015.
16. Fonnes T, Berg HF, Bredholt T, Edqvist PD, Sortland K, Berg A, Salvesen HB, Akslen LA, Werner HMJ, Trovik J, et al: Asparaginase-like protein 1 is an independent prognostic marker in primary endometrial cancer, and is frequently lost in metastatic lesions. Gynecol Oncol 148: 197-203, 2018.

17. Evtimova V, Zeillinger R, Kaul S and Weidle UH: Identification of crash, a gene deregulated in gynecological tumors. Int J Oncol 24: 33-41, 2004.

18. Weidle UH, Evtimova V, Alberti S, Guerra E, Fersis N and Kaul S: Cell growth stimulation by CRASH, an asparaginase-like protein overexpressed in human tumors and metastatic breast cancers. Anticancer Res 29: 951-963, 2009.

19. Livak KJ and Schmittgen TD: Analysis of relative gene expression data using real-time quantitative PCR and the 2(-Delta Delta C(T)) method. Methods 25: 402-408, 2001

20. Lois C, Hong EJ, Pease S, Brown EJ and Baltimore D: Germline transmission and tissue-specific expression of transgenes delivered by lentiviral vectors. Science 295: 868-872, 2002.

21. Song X, Li L, Shi Q, Lehmler HJ, Fu J, Su C, Xia X, Song E and Song Y: Polychlorinated biphenyl quinone metabolite promotes p53-dependent DNA damage checkpoint activation, S-Phase cycle arrest and extrinsic apoptosis in human liver hepatocellular carcinoma HepG2 cells. Chem Res Toxicol 28: 2160-2169, 2015.

22. Fotedar A, Cannella D, Fitzgerald P, Rousselle T, Gupta S, Dorée $\mathrm{M}$ and Fotedar R: Role for cyclin A-dependent kinase in DNA replication in human S phase cell extracts. J Biol Chem 271: 31627-31637, 1996.

23. Guinn BA and Mulherkar R: International progress in cancer gene therapy. Cancer Gene Ther 15: 765-775, 2008.

24. Li W, Irani S, Crutchfield A, Hodge K, Matthews W, Patel P, Zhang YJ and Stone E: Intramolecular cleavage of the hASRGL1 homodimer occurs in two stages. Biochemistry 55: 960-969, 2016.

25. Saarela J, Laine M, Tikkanen R, Oinonen C, Jalanko A, Rouvinen $\mathrm{J}$ and Peltonen L: Activation and oligomerization of aspartylglucosaminidase. J Biol Chem 273: 25320-25328, 1998.

This work is licensed under a Creative Commons Attribution-NonCommercial-NoDerivatives 4.0 International (CC BY-NC-ND 4.0) License. 